\title{
Single Incision Laparoscopic Appendectomy Using a New Multi-joint Articulating Instrument
}

\author{
Hyeong Yong $\operatorname{Jin}^{1} \cdot$ Chul Seung Lee ${ }^{1}$ Yoon Suk Lee ${ }^{1}$ \\ Received: 18 February 2021 / Accepted: 20 April 2021 / Published online: 19 May 2021 \\ (C) 2021 The Author(s)
}

Keywords Articulating instrument $\cdot$ ArtiSential $^{\circledR} \cdot$ Appendectomy $\cdot$ Single incision

\section{Background}

Appendectomy is the most common emergent abdominal surgery worldwide, and almost 250,000 appendectomies were performed in the USA each year. ${ }^{1,2}$ According to several previously published randomized controlled trials and metaanalyses reports, single-incision laparoscopic appendectomy (SILA) has potential advantages of shorter length of hospital stay and better cosmetic satisfaction than conventional threeport laparoscopic appendectomy. ${ }^{3,}{ }^{4}$ However, SILA is still technically challenging because of internal collision between laparoscopic instruments. Due to these technical difficulties, SILA has disadvantages of longer operating times and higher conversion rates. As an alternative, new laparoscopic articulating instruments were developed.

\section{Purpose}

Conventional straight-fixed laparoscopic instruments have disadvantages of reduced dexterity, limited freedom of movement, and uncomfortable ergonomics. Therefore, it was hard for surgeons to get an effective angle and make effective traction and counter-traction during laparoscopic surgery. To overcome these limitations, a surgical robot system, the da Vinci (Intuitive Surgical Inc., Sunnyvale, CA), was developed. Robot system provides high-definition three-dimensional vision with enhanced dexterity, multi-joint instruments, tremor reduction, and comfortable ergonomics. However, it

Yoon Suk Lee

yslee@catholic.ac.kr

1 Department of Surgery, Division of Colorectal Surgery, Seoul St. Mary's Hospital, College of Medicine, The Catholic University of Korea, Seoul, Republic of Korea has cost versus benefits issue. A new laparoscopic articulating instrument has multi-joint structure that are synchronized with the surgeon's hand, wrist, and finger movement. With this structure, it can provide $360^{\circ}$ of movement. Its multiple degrees of movement allows a wide range of surgical procedures like using a robotic arm. In addition, it has cost-effectiveness compared to robotic surgery. In this video, we intended to show how to overcome internal collision and make a good surgical view through a new laparoscopic articulating instrument during SILA.

\section{Materials and Methods}

We used the ArtiSential ${ }^{\circledR}$ (LIVSMED Inc., Republic of Korea), a new laparoscopic articulating instrument which is registered as a class I medical device with the Korea Food and Drug Administration in 2019 (Fig. 1). ${ }^{5}$ Also, it achieved USFDA approval in June 2020. The instrument can be used with any $8 \mathrm{~mm}$, or larger, sized trocar.

In port placement, we applied the Glove port ${ }^{\circledR}$ (Nelis Corp., Republic of Korea) (Fig. 2). It consists of three 5-mm-sized ports and one $12-\mathrm{mm}$-sized port. Therefore, it is possible to freely use a stapling device according to surgeon's preference. The articulating instrument is placed on the left side, with surgeon's non-dominant hand.

The articulating instrument is US\$578, single port (Glove port $^{\circledR}$ ) is US $\$ 260$, conventional laparoscopic instrument is US\$210, and the conventional laparoscopic three ports are US\$245 in Republic of Korea. There is no difference between the port prices, but the price of the instrument is expensive for the new instrument. However, it is very cheap compared to a robotic system.

This video article was approved by the Institutional Review Board of the Ethics Committee of the College 
Fig. 1 The laparoscopic multijoint instrument $\left(\right.$ ArtiSential $^{\circledR}$ )

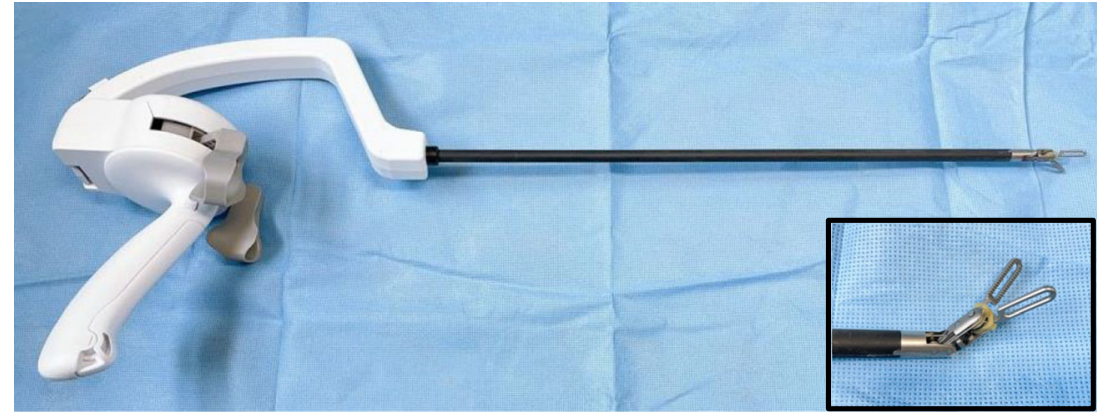

of Medicine, The Catholic University of Korea (KC21ZASI0029).

\section{Results}

In this video, we presented the steps of SILA using a new laparoscopic articulating instrument.

\section{Conclusions}

Single-incision laparoscopic appendectomy using a new laparoscopic articulating instrument (ArtiSential ${ }^{\circledR}$ ) is safe and technically feasible. Furthermore, it can be applied in various abdominal surgeries requiring wider range of movement.

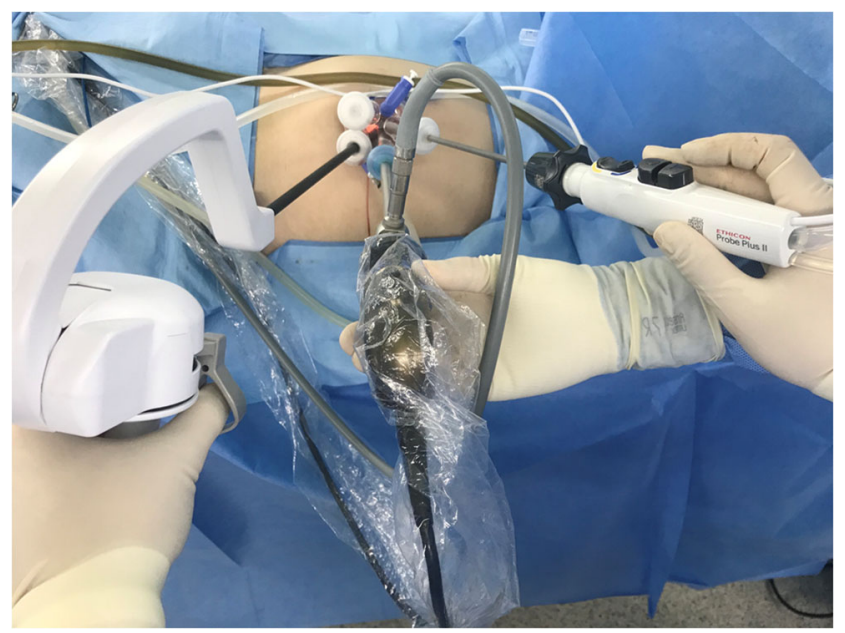

Fig. 2 Port placement. The ArtiSential ${ }^{\circledR}$ is placed on the left side, with surgeon's non-dominant hand
Supplementary Information The online version contains supplementary material available at https://doi.org/10.1007/s11605-021-05026-w.

\section{Declarations}

Conflicts of Interest and Source of Funding The authors have no potential conflicts of interest (financial, professional, or personal), and no company has provided any financial arrangements for this study.

Open Access This article is licensed under a Creative Commons Attribution 4.0 International License, which permits use, sharing, adaptation, distribution and reproduction in any medium or format, as long as you give appropriate credit to the original author(s) and the source, provide a link to the Creative Commons licence, and indicate if changes were made. The images or other third party material in this article are included in the article's Creative Commons licence, unless indicated otherwise in a credit line to the material. If material is not included in the article's Creative Commons licence and your intended use is not permitted by statutory regulation or exceeds the permitted use, you will need to obtain permission directly from the copyright holder. To view a copy of this licence, visit http://creativecommons.org/licenses/by/4.0/.

\section{References}

1. Mortality of emergency abdominal surgery in high-, middle- and low-income countries. Br J Surg 2016;103:971-988.

2. Addiss DG, Shaffer N, Fowler BS, Tauxe RV. The epidemiology of appendicitis and appendectomy in the United States. Am J Epidemiol 1990;132:910-925.

3. Deng L, Xiong J, Xia Q. Single-incision versus conventional threeincision laparoscopic appendectomy: a meta-analysis of randomized controlled trials. J Evid Based Med 2017;10:196-206.

4. Aly OE, Black DH, Rehman H, Ahmed I. Single incision laparoscopic appendicectomy versus conventional three-port laparoscopic appendicectomy: a systematic review and meta-analysis. Int J Surg 2016;35:120-128.

5. Jin HY, Lee CS, Lee YS. Laparoscopic extended right hemicolectomy with D3 lymph node dissection using a new articulating instrument. Tech Coloproctol 2021;25:235-237.

Publisher's Note Springer Nature remains neutral with regard to jurisdictional claims in published maps and institutional affiliations. 